\title{
FÓRUM DE DISCUSSÃO ONLINE: experiências e formação con- tinuada em matemática
}

DISCUSSION FORUM ONLINE: experience and continued training in mathematics. FORODEDISCUSIÓNENLÍNEA: experiencias y formación contínua en matemáticas.

\author{
Gisele Pereira de Oliveira Xavier \\ Mestre em Educação, Contextos Contemporâneos e Demandas Populares (PPGEduc/UFRRJ). \\ São João de Meriti-RJ, Brasil. \\ gisele_po@msn.com \\ Marcelo Almeida Bairral \\ Professor Doutor da Universidade Federal Rural do Rio de Janeiro (UFRRJ). \\ Seropédica-RJ, Brasil. \\ mbairral@ufrrj.br
}

\begin{abstract}
RESUMO: O objetivo deste artigo é elucidar reflexões de experiências docentes que podem ser encontradas em interações argumentativas em fóruns de discussão online. Os dados foram coletados em um fórum para formação continuada em Matemática de professores da rede estadual que atuavam na EJA no $1^{\circ}$ semestre de 2014 . A análise evidencia o potencial argumentativo que as interações estabelecidas na reflexão online podem trazer para a aprendizagem dos envolvidos. Particularmente, reflexões de cunho argumentativo têm se mostrado um campo discursivo fértil para socialização e aprimoramento de práticas e experiências profissionais. Reconhecer singularidades discursivas nas interações é importante, inclusive, na construção de estratégias para manter a cumplicidade do coletivo profissional.
\end{abstract}

PALAVRAS-CHAVE: Fórum de discussão. Formação continuada. Matemática. Interações online.

ABSTRACT: The aim of this paper is to elucidate reflections of teaching experiences that can be found in argumentative interactions in online discussion forums. Data were collected on a forum for in service mathematics teachers who worked with youth and adult education in the first semester of 2014 in state schools. The analysis highlights the potential of argumentative interactions established in the online reflection and it importance for the learning of the participants. Particularly argumentative reflections have shown a fertile discursive field for socialization and improvement of practices and professional experiences. To recognize discursive singularities in online interactions is important, even in the construction of strategies to keep the complicity of the professional collective.

KEYWORDS: Discussion forum. In service teacher education. Mathematics. Online interactions.

RESUMEN: El objetivo de este trabajo es presentar reflexiones de experiencias de enseñanza que se pueden encontrar en las interacciones argumentativos en los foros de discusión en línea. Los datos se recogieron en un foro para la formación continua de profesores de matemáticas que actuaron en la educación de jóvenes y adultos en el primero semestre de 2014 en escuelas estatales. El análisis pone de relieve el potencial que las interacciones argumentativas establecidas en la reflexión en línea pueden traer al aprendizaje de los involucrados. En particular, la naturaleza argumentativa de las reflexiones ha demostrado ser un campo discursivo fértil para la socialización y la mejoría de las prácticas y experiencias profesionales. Reconocer singularidades en las interacciones discursivas es importante, incluso para la construcción de estrategias para mantener la complicidad del colectivo profesional.

PALABRAS CLAVE: Foro de discusión. Educación continua. Matemática. Interacciones en línea. 


\section{1| INTRODUÇÃO}

Este artigo é um recorte de uma pesquisa ${ }^{1}$ (XAVIER, 2016) realizada com objetivo de analisar interações de docentes em fóruns de discussão de formação continuada em matemática para a Educação de Jovens e Adultos (EJA) ${ }^{2}$. Particularmente, ilustra reflexões de professores explicitadas em interações online em um fórum, principal meio utilizado para reflexões a distância dos envolvidos.

Sendo o fórum de discussão um ambiente virtual que possibilita a interação dos participantes, o compartilhamento de suas experiências, conhecimentos e práticas (BAIRRAL, 2012), este pode proporcionar aos envolvidos novas formas de aprendizado. Neste processo, sublinham Scheffer, Bressan e Corrêa (2010), é necessário promover uma reflexão sobre a ação docente e sobre suas concepções de ensinar e de aprender, pois é nessa ação que se reflete a atuação dos professores.

Como forma de promover essa reflexão profissional e de dar visibilidade às suas práticas, a dinâmica no ambiente virtual do Programa analisado ${ }^{3}$ era composta por uma rotina que consistia no desenvolvimento de algumas tarefas: participação no fórum temático ${ }^{4}$, desenvolvimento do plano de ação e avaliação do plano de ação. Cada fórum era mediado por um tutor, que também exercia a função de professor de matemática ${ }^{5}$. A questão que fomentou a análise foi: que traços de reflexões de experiências docentes podem ser encontradas em interações argumentativas de professores de matemática em formação continuada interagindo online em um fórum?

\section{2| UMA REVISÃO DE LITERATURA}

Aqui será apresentada uma síntese do mapeamento de produções científicas nos últimos cinco anos que envolvem as temáticas: formação continuada de matemática em ambientes virtuais e fórum de discussão. Quanto à primeira temática, tem-se os trabalhos de Campelo (2011), Oliveira (2012), Medeiros (2012) e Miskulin, Silva e Rosa (2009) que tiveram o foco na formação continuada em matemática por meio de ambientes virtuais. Todas as pesquisas utilizaram os registros dos fóruns de discussão em suas análises.

Campelo (2011) e Oliveira (2012) verificaram que, mediante o compartilhamento de ideias no decorrer do fórum temático, os envolvidos dialogaram e repensaram suas trajetórias durante a formação e perceberam algumas lacunas de aprendizado. A pesquisa de Medeiros (2012) observou que os envolvidos, além de construírem os conceitos pertinentes ao conteúdo, também discutiram as possibilidades de desenvolver esse aprendizado na educação básica. Miskulin, Silva e Rosa (2009) também destacam que o compartilhamento das histórias, experiências e práticas ajudam os envolvidos a ressignificarem suas práticas docentes.

\footnotetext{
${ }^{1}$ Realizada com apoio da Fundação CECIERJ e do CNPq.

${ }^{2}$ O Programa de Formação Continuada para a EJA (Ensino Médio) foi desenvolvido pela SEEDUC/RJ em parceria com a Fundação CECIERJ visando à melhoria da qualidade da modalidade e do desenvolvimento profissional dos docentes. O curso era formado por quatro módulos de Matemática e uma disciplina sobre EJA (Discussões e Práticas), posteriormente substituída por pela discussão das demandas e desafios de ensinar Matemática na EJA. O curso era semipresencial. À distância os cursistas eram acompanhados e participavam das tarefas no ambiente virtual de aprendizagem. E presencialmente se reuniam em quatro encontros bimestrais.

${ }^{3}$ Veja Bairral et al. (2016) para ver outro tipo análise deste Programa de formação.

${ }^{4} \mathrm{O}$ Fórum Temático era um espaço destinado à discussão de questões didáticas, práticas e conceituais sobre a disciplina. Cada fórum possuía uma questão norteadora que englobava os objetivos das unidades.

${ }^{5} \mathrm{~A}$ primeira autora deste artigo atuou como tutora em um desses fóruns.
} 
Embora os trabalhos tenham focado a formação continuada em Matemática mediante ambientes virtuais nenhuma das pesquisas teve como foco a análise das interações nestes cenários. Quanto à temática fórum de discussão optou-se por aproveitar as pesquisas que buscavam analisar as interações em ambientes virtuais. Através das produções encontradas, foi observado que o fórum deve ser apresentado não como uma cobrança avaliativa, mas como um processo que possibilita que os pares possam se desenvolver (SALDANHA, 2011). Se o curso online propõe promover a interação é esperado que o tutor não foque na "instrução", mas sim na promoção de estratégias que possibilitem o aprender experimentando, compartilhando, fazendo (LOBATO, 2012). No fórum os alunos dão a vida ao ambiente, e os tutores são incentivadores nesse processo interativo (SALDANHA, 2011). Nesse sentido, o tutor deve estar atento para melhor aproveitar as informações e nortear a discussão (SILVA, 2010; FÉLIX, 2011).

Silva (2010) destaca que, embora os participantes interajam, pode ocorrer de alguns não responderem as questões norteadoras. A autora destaca, ainda, que o tutor deve manter uma participação constante, de forma que incentive o desenvolvimento do pensamento e aprendizagem. No entanto, esta interação não deve estar centrada em responder apenas o tutor e as questões. Os alunos devem ser incentivados a criarem articulações argumentativas entre si (FÉLIX, 2011). Pois, quando motivados, os cursistas ${ }^{6}$ se sentem mais à vontade para interagir (liderança partilhada), dessa forma, todos passam a serem vistos como autores e coautores nesse processo construtivo (SILVA, 2010; SALDANHA, 2011).

Vale destacar que a quantidade de mensagens não caracteriza a manifestação de uma rede argumentativa (SANTOS, 2012) e contribuições significativas (SILVA, 2012). Uma maneira de fomentar a participação e motivar o cursista para a discussão é adotando algumas posturas, exemplo: perguntando o que levou a concordar ou discordar do colega, o que mais chamou atenção, pedir que busque exemplos ou compartilhe algum material, se já realizou ou teve uma experiência similar e pedir que compartilhe. Nesse sentido, Bezerra, Santos e Fernandes (2013, p. 84) sinaliza a "importância da interação no Fórum de discussão como prática potencializadora da ressignificação das intervenções através das reflexões feitas em um grupo colaborativo".

Nota-se que mesmo havendo produções sobre a investigação em fórum de discussão, ainda é um tema que carece de pesquisas, pois ainda são poucas as investigações que analisam reflexões e experiências profissionais compartilhadas mediante interações em fórum online.

\section{3| INTERAÇÃO E APRENDIZADO EM UM FÓRUM}

A pesquisa está orientada pela teoria histórico-cultural de Vigotski, pois assumimos que mudanças que ocorrem ao longo da trajetória do sujeito estão relacionadas às interações que ocorrem entre ele (homem), a sociedade, a sua história de vida e a cultura. Em um fórum de discussão a interação é vista como "qualquer intercâmbio comunicativo estabelecido entre os atuantes de um ambiente virtual, seja a partir da dinâmica de trabalho proposta nas tarefas de formação, seja de outro interesse do interlocutor" (BAIRRAL, 2013, p. 39). Portanto, a interação não é uma cena estática e sem propósito. Ela é dinâmica e possui intencionalidades e diferentes formas de envolvimentos dos interlocutores. Os envolvidos no processo interativo, participantes e tutores modificam as relações que se estabelecem no ambiente.

Conforme as interações se estabelecem, novas observações, apontamentos, concordâncias e discordâncias aparecem. A reflexão vai se instaurando e o conhecimento vai sendo moldado, pois

${ }^{6}$ Participantes do ambiente virtual. 
a ação desenvolvida por um participante serve de complementação para o trabalho de outros participantes (KENSKI, 2003 apud ZULATTO, 2010). Como sublinham Mello, Braga e Gabassa (2013, p. 3), "o conhecimento não está no sujeito nem no objeto, mas na interação entre ambos." Por meio da troca de mensagens o grupo pode interagir e discutir o que é proposto. Bairral (2007, p. 80) define o Fórum de discussão como um "espaço de socialização contínua de práticas nas quais os interlocutores podem utilizar e integrar, diferentemente, informações do próprio cenário ou de fora dele." Vale lembrar que neste espaço a interação é assíncrona, isto é, não acontece em tempo real. O participante pode interagir em um momento diferente das ações já realizadas. Portanto, a aprendizagem ocorre quando o interlocutor torna próprio algo que viu, discutiu e (re)significou (VYGOTSKY, 1984). À medida que o sujeito apropria-se do conhecimento ele também cria, transforma e reelabora suas práticas sociais, dando novas indicações para o seu desenvolvimento (SOUZA et al., 2010). Souza destaca, ainda, que a apropriação é concomitante ao social e individual, uma vez que os significados vão agregando novos sentidos, dependendo das experiências que cada um possui.

O conhecimento profissional do professor, em particular, se desenvolve a partir de momentos concretos de aprendizagem (BAIRRAL, 2007, p. 47). O conhecimento se forma "integrando as características do discurso e os processos interativos de cada espaço discursivo do cenário." Com isso, a interação deve desenvolver nos professores a estruturação de ações profissionais comprometidas com modificações no processo de ensino-aprendizagem. Isto é, além da reflexão, influenciar mudanças em sua prática pedagógica.

Para Vigotski o homem se constitui humano por uma dupla mediação: mediação da linguagem e mediação do outro. Dessa forma, a palavra "nunca se refere a um objeto isolado mas a todo um grupo ou classe de objetos" (VIGOTSKI, 2001, p. 9). Ela apresenta finalidade e características que devem ser levadas em consideração. O autor destaca que "a palavra é o fim em que a ação culmina” (VYGOTSKY, 1993 apud GÓES; CRUZ, 2006, p. 36). Sendo assim, a linguagem é um instrumento de mediação do pensamento.

Nota-se o quanto é importante considerar o contexto na hora de realizar a análise nos espaços virtuais de aprendizagem. Como Souza et al. (2010, p. 459) menciona "os processos humanos têm origem nas interações sociais e devem ser compreendidos em seu caráter histórico-cultural." Sendo assim, cada grupo possui um modo característico de falar. Como os sujeitos da pesquisa são professores de matemática formados e em aperfeiçoamento, suas falas diferem, por exemplo, de um grupo formado por professores de linguagens. Woods (1999) complementa que é necessário compreender o contexto, pois a situação pode afetar as perspectivas e os comportamentos, e perspectivas, também podem afetar as situações. Na análise das palavras é importante considerar os sujeitos e o contexto de produção das interações. Barberà, Badia e Mominó (2001) acrescenta dizendo que para que essa compreensão se efetive é importante considerar, também, que interação está sendo produzida, além de verificar que conhecimentos estão sendo ativados e que processos cognitivos os participantes estão realizando em suas ações no espaço virtual. Além de considerar todas as interações estabelecidas com os outros elementos do contexto do fórum (textos, imagens, vídeos, etc).

\section{4 | CAPTURANDO MENSAGENS ARGUMENTATIVAS E INFORMATIVAS}

A análise ilustrada neste artigo realizou-se da seguinte maneira: foi verificado o fórum que mais teve participação dos cursistas durante o módulo, no caso, o fórum ${ }^{7}$ que tratava de Função Polinomial

${ }^{7}$ Cada fórum temático englobava conteúdos referentes até três unidades. O tempo de duração de cada fórum era de doze (12) dias. O fórum partia de uma questão norteadora que englobava os objetivos das unidades. 
do $2^{\circ}$ grau foi o que teve mais participações. Em seguida, foi mapeado o quantitativo de mensagens argumentativas e informativas, e, a partir delas, foram considerados elementos que poderiam trazer informações sobre o desenvolvimento formativo dos grupos. $\mathrm{Na}$ análise qualitativa, as tipologias ajudam o investigador, e até mesmo os tutores, a identificarem elementos que podem gerar a continuidade da discussão (BAIRRAL, 2013). Com base nisso, as mensagens de cunho argumentativo merecem ser observadas com cautela a fim de que possam ser levantados os elementos que ajudam no estabelecimento de conexões conceituais e no aprimoramento da reflexão que está sendo realizada no fórum.

Dois grupos tiveram suas mensagens analisadas de forma que fosse possível perceber se eram argumentativas ou informativas. Foi observado se as mensagens expressavam apenas opinião sem uma reflexão crítica do que foi exposto, se divulgavam algum material (informativas) e se contemplavam novos questionamentos, ampliavam a discussão fazendo análise ou simulações do que foi dito (argumentativas). Partindo desse princípio foram catalogadas de forma quantitativa essa análise qualitativa dos discursos de ambos os grupos. Veja o quadro abaixo:

Quadro 1 - Mensagens argumentativas/informativas - Grupo 1 e 2

\begin{tabular}{|c|c|c|}
\hline Tipo de mensagens & Grupo 1 & Grupo 2 \\
\hline Cunho argumentativo & 80 & 67 \\
\hline Cunho informativo & 64 & 67 \\
\hline Total de postagens & 144 & 134 \\
\hline
\end{tabular}

Fonte: Elaborado pelos autores.

Uma coisa interessante foi perceber que, no Grupo 2, o quantitativo de mensagens argumentativas e informativas foi muito equilibrado. Vale ressaltar que a análise foi realizada levando em consideração o quantitativo geral do fórum. Com isso, até as mensagens dos tutores foram consideradas na análise de ambos os grupos. Veja abaixo um recorte de uma interação realizada no grupo, na qual é possível perceber como a comunicação foi estabelecida de forma bem equilibrada.

Cursista H: "Boa tarde Tutor $\mathbf{X}$ e colegas. Ao ler o material do professor, optei por uma atividade que vem de encontro a maioria da minha turma, pois $60 \%$ deles trabalham ${ }^{10} \mathrm{como}$ vendedor, em alguma loja do bairro, que não é exatamente do material do professor, mais tem tudo a ver com o dia a dia deles. Questionamento $\urcorner$ a $\urcorner$ um vendedor recebe mensalmente um salário composto de duas partes: uma parte fixa, no valor de um salário mínimo, que é $\mathrm{R} \$ 724,00$ e uma parte variável, que corresponde a uma comissão de $8 \%$ do total de vendas que ele fez durante o mês. I) $\neg$ Expressar a equação que representa seu salário mensal. II) $\neg$ Calcular o salário do vendedor sabendo que durante um mês ele vendeu $R \$ 10.000,00$ em produtos. Modelando: Salário mensal: S Salário fixo: $\mathrm{R} \$ 724,00$. Parte variável: $+8 \%$ (do total de vendas, chamando de $x$ ). Item I $\neg$ Logo: $S=724+0,08 x$. Item II $\neg$ Se $x=10.000$, teremos: $S=724+0,08.10 .000$, então: $S=724+800=1.524$. Logo o salário desse vendedor é de $R \$ 1.524,00$. Apenas revisei porcentagem e não precisei nem usar mais exemplos, passei atividades e eles desenvolveram muito além da expectativa. Abraços, Cursista H".

Cursista K: "Bom dia Cursista $\boldsymbol{H}$ e demais colegas. Gostei também muito desta atividade. Parabéns pela sugestão. Obrigada! Um abraço, Cursista K".

${ }^{10}$ Sublinhados e negritos feitos pelos autores. 
Cursista Z: "Boa tarde Cursista H, tutora Josiane e colegas cursistas. Respondendo à postagem da colega Cursista H, Rio de Janeiro ᄀ domingo, 30 de março 2014, 16:06. Realmente, uma parte considerável dos alunos trabalham com vendas, assim sendo, teu exemplo vem de encontro com o cotidiano deles e também trabalhei em exemplo parecido com o teu. Um abraço. Cursista Z".

Cursista A': "Boa noite Cursista H. Gostei muito da atividade, simples de fácil compreensão. Parabéns. Um abraço, Cursista A'”.

No recorte acima, é possível notar através dos elementos que foram sublinhados na mensagem do Cursista $\mathrm{H}$, que ele buscou justificar sua resposta, compartilhando com o grupo o porquê de sua decisão na escolha da atividade, o que levou em consideração, como se deu o processo de aplicação da atividade e as impressões que teve durante o desenvolvimento dela. Alguns elementos argumentativos que justificam sua opinião também podem ser vistos na mensagem do Cursista Z. Logo, pelo que já foi exposto, foi visto que este tipo de mensagem é de cunho argumentativo. Já os Cursistas $\mathrm{K}$ e A' apenas expõem que gostaram da atividade, mas não fornecem os elementos que justificam o porquê se identificaram. Por conta disso, como já foi exposto, esse tipo de mensagem é de cunho informativo.

Com a leitura do recorte acima é possível perceber que o tipo de mensagem foi bem equilibrado. Este diálogo, por exemplo, foi estabelecido a partir de duas mensagens de cunho argumentativo e duas de cunho informativo.

No Grupo 2 os cursistas adotaram uma postura de sempre retornar aos colegas dizendo se gostaram ou não da atividade e se aplicaram em aula. Esboçavam uma opinião, mas sem entrar em muitos detalhes e agregar novas informações. Nesse fórum, alguns dos cursistas, ao invés de postar suas respostas às questões norteadoras no corpo do próprio texto, tiveram uma nova postura, anexar um arquivo doc. contendo as respostas. Veja a seguir:

Cursista V: ITEM b) Fórum Temático 3.docx

"Olá Pessoal. Estou enviando anexo a resposta ao item b) do nosso fórum. Abraço a todos".

Cursista W: Gráfico da Função Afim.doc

"Tutor $\mathrm{X}$ e demais colegas, bom dia! Respondido o item b) do Fórum Temático 3 que está no documento em anexo".

Sendo um fórum um ambiente que o participante goza de um tempo maior para interagir, espera-se que ele acompanhe. Mas, embora a plataforma Moodle possibilite que sejam visualizados os arquivos que foram realizados downloads e onde os cursistas transitaram no ambiente, não é garantido dizer que eles de fato leram tudo, mesmo havendo efetuado os downloads. No entanto, no fórum do Grupo 2 mesmo com essa prática de anexar o arquivo, é possível perceber que os cursistas não só efetuaram o download mas leram, pois alguns retornaram trazendo suas observações as questões compartilhadas pelos colegas como pode ser conferido na figura abaixo.

Cursista P: Observando gráficos forum3 José Ricardo.docx ${ }^{11}$

"Resposta b) Bem! Como não foi especificado o tipo de tratamento dado a solução me senti a vontade em minhas escolhas. Segue em anexo".

\footnotetext{
${ }^{11}$ Como este momento de análise é posterior ao que ocorreu, a pesquisadora não tem mais acesso aos materiais que foram anexados no ambiente virtual do fórum em questão, tendo acesso somente às mensagens. Por esse motivo, a sugestão que foi anexada pelo cursista não irá compor a análise.
} 
Cursista $\boldsymbol{H}$ : "Boa tarde Cursista $\boldsymbol{P}$, também gostei muito das suas duas maneiras de trabalhar função, porem a segunda maneira de ensinar esse tópico, acho pouco trabalhosa pois requer um pouco mais de tempo e habilidade. Abraços, Cursista H".

Na mensagem acima é possível perceber que o Cursista $\mathrm{H}$ visualizou a sugestão do colega $\mathrm{P}$ e, e, em seguida, deixou suas observações pontuando que a segunda estratégia utilizada pelo colega iria requerer dos alunos um pouco mais de habilidade e domínio do conteúdo de função afim. Uma consideração que deve ser relevada por conta das necessidades do público de EJA. Contudo, se os alunos já dominarem o assunto é interessante desafiar o raciocínio.

Já no caso do Grupo 1, as mensagens de cunho argumentativo se evidenciaram mais. Foi possível notar que no decorrer do fórum o tutor além de ressaltar se a mensagem do cursista foi interessante ou não, ele (o tutor) adotou como postura sempre retornar com uma sugestão, uma pergunta, e até mesmo pedir que o cursista retornasse após a aplicação da atividade com sua turma, para compartilhar suas reflexões sobre a ação com o grupo. É provável que essa postura tenha contribuído para que as mensagens de cunho argumentativo se tornassem mais presentes, uma vez que elas desenrolaram novas conexões discursivas.

Foi também possível observar que os participantes do Grupo 1 demonstraram em suas postagens aproveitar as sugestões dos colegas com suas turmas. Houve a presença de muita troca de materiais (sites, vídeos, questões etc.) como pode ser contemplado na interação abaixo:

Cursista W: "Respondendo o item a, pude observar que os alunos conseguem compreender melhor a definição de função através de sua realidade. Mostrei um exemplo de um taxista que a cada $\mathrm{km}$ ele cobraria $R \$ 3,00$. Colocando isso no quadro, chamei de taxa de taxi $(y)=3 x$. A partir daí conseguimos iniciar o entendimento de função".

Cursista D: "Olá Cursista W, usei esse exercício em sala e mostrei a eles que o coeficiente linear, nessa expressão, é zero. Foi legal! Abraços!".

Bairral (2013) focaliza que a identificação das tipologias é essencial para se pensar em estratégias para dar continuidade na discussão e aprimoramento do aprendizado nos fóruns temáticos. Todavia, ressalta que "situações de aprendizagem variadas e desafiadoras também podem potencializar intervenções argumentativas" (BAIRRAL, 2013, p. 44). Sendo assim, é possível perceber que as tipologias podem ajudar a interpretar e explicar um discurso. Pois, através dos elementos (elementos adquiridos a partir das tipologias) percebidos nos diálogos pode-se (re)elaborar ações para intervenções nos fóruns e assim conseguir novos caminhos para que a discussão seja fomentada.

Cursista S: "Respondendo a questão a: Acredito que se trabalharmos situações com a qual nossosalunospossamdeidentificar, sejaumcaminhorazoávelparaummelhorentendimentodos assuntosa seremtratados. Achoque umproblemaa sertrabalhadoem sala deaulaque sejainteressante, seja uma análise de uma conta deluz, para podermosfazera associação a funçãoafim".

Tutor Y: "Olá Cursista S boa noite. A análise de uma conta de luz seria uma boa atividade. Mas o cálculo com números decimais poderia atrapalhar o entendimento do conceito de função afim. Uma saída seria utilizar a calculadora como recurso para facilitar as contas o que você acha? Abraços, Tutor Y".

Neste recorte é possível observar que o tutor chama a atenção do cursista para o fato de que no exemplo sugerido (conta de luz) há outros conhecimentos que devem ser levados em consideração, como é o caso das operações com os números decimais. Um conteúdo que normalmente 
os alunos apresentam certa desestabilidade em realizar operações. Por conta disso, o tutor aproveita para sugerir a utilização da calculadora. Uma maneira de romper com a falta de habilidade de alguns alunos e oportunizar que a utilização da sugestão ocorra da forma como o cursista espera, além de trazer outro assunto para a discussão que é a utilização deste recurso um pouco polêmico por parte dos professores de matemática. Abaixo poderá ser visto a continuidade deste diálogo.

Cursista S: "Olá Tutor Y, com certeza o uso da calculadora é um ferramenta que, principalmente no neja, deve ser utilizado com recurso".

Cursista T: "Já liberei o uso da calculadora em todas as minhas aulas e avaliações a um bom tempo. Em certas situações até pode ser um pouco prejudicial, mas... tá liberado!".

Como pode ser percebido acima, o Cursista S respondeu a sugestão do tutor com uma mensagem de cunho informativo. Apenas comentou que seria interessante, mas não teceu maiores comentários nem para o fato que a utilização da conta de luz poderia recair (operações com decimais), nem compartilhou sua opinião com mais detalhes sobre a utilização da calculado.

Uma coisa interessante é que embora o Cursista S não tenha argumentado mais sua opinião, o Cursista T compartilhou que permite sua utilização nas aulas e até mesmo em suas avaliações. Mas, um fato que merece destaque, é que ele comenta que "em certas situações até pode ser um pouco prejudicial".

É importante destacar que embora o tutor tivesse fomentado a discussão neste primeiro momento, não houve mais abordagens do tutor após o compartilhamento dos cursistas em relação ao assunto instigado. Uma pena, pois o Tutor $Y$ poderia ter indagado ao cursista, por exemplo: o porquê seria prejudicial? Se o aluno não conhece as operações e não domina alguns conhecimentos matemáticos, ou até mesmo conhecimentos em relação à utilização da calculadora, o raciocínio lógico não seria instigado, isto é, de nada adiantaria ter a disposição à calculadora. Poderia haver outras intervenções para fomentar a continuidade do discurso, e a abordagem de outras perspectivas para a formação continuada.

Como visto ao longo deste processo interativo, o grupo vai se desenvolvendo a partir das relações que estabelecem uns com os outros. Partindo disso, é possível compreender que embora os elementos percebidos nessas interações sejam capazes de fornecer informações para novas intervenções, cada grupo evidenciará elementos distintos, como também similares, o que é interessante e importante destacar é que essas informações podem ser utilizadas para reorientar a discussão, assim como perceber o desenvolvimento individual e também de forma geral do grupo, possibilitando a intervenção com novas propostas de forma a ajudar e consolidar que cada participante se desenvolva e ative seu conhecimento.

Com base no que foi exposto é possível perceber que essas sutilezas percebidas nos discursos fornecem elementos para que o profissional, neste caso, o tutor, possa interpretar a postagem e potencializar a zona de desenvolvimento real dos envolvidos. Na sequência de interações abaixo, é possível observar esse "crescimento" a partir de uma abordagem do tutor.

Cursista U: "Olá pessoal, respondendo a questão A) Conversando com os alunos durante as unidades 12 e 13, percebi que a maioria trabalha ganhando comissão. A atividade, então que sugiro, para que eles se interessem mais em resolver o problema e se entretenham ao mesmo tempo, seja a análise de uma situação em que um trabalhador receba sua remuneração de acordo com uma porcentagem de suas vendas mais um valor fixo mensal. Após estudar os dados, deverão montar o seu gráfico e analisar o quanto cresce o valor de sua remuneração de acordo com as vendas". 
Tutor Y: "Olá Cursista $\boldsymbol{U}$, boa noite. Muito boa a atividade criada por você. Já aplicou? Compartilhe aqui como foi a reação da turma. Abraços, Tutor Y”.

Cursista U: "Olá Tutor Y; ainda não, mas espero aplicar nesta semana. Pretendo dividi-los em grupos de forma que cada grupo possua um percentual de comissão diferente, e que no fim possamos comparar os seus gráficos. Assim que finalizar a atividade posto os comentários”.

No diálogo acima o tutor instiga a continuidade da discussão incentivando que o cursista compartilhe suas impressões após a aplicação da atividade. Na segunda mensagem do Cursista U, é possível verificar que ele fornece mais riquezas de detalhes sobre as estratégias que utilizará para desenvolver suas sugestões. Elementos que na primeira mensagem não apareceram.

Neste recorte, é notável o quanto uma intervenção pode contribuir para que as ideias iniciais sejam repensadas e amadurecidas. Na formação continuada isso é crucial. Pensar sobre a ação antes de executá-la, analisar as possibilidades, o contexto e a viabilidade são importantes para que o planejamento do professor tenha mais chances de alcançar o objetivo a que se propõe.

\section{5 | CONSIDERAÇÕES FINAIS}

Neste artigo ilustramos e analisamos reflexões sobre experiências que podem ser explicitadas e compartilhadas mediante interações online em fóruns de discussão visando o desenvolvimento profissional para atuação na EJA. As reflexões manifestadas pelos educadores estiveram circunscritas à socialização e análise online de recursos didáticos variados, à sugestão ou realização de atividades variadas, a comentários de resultados de suas implementações ou de um colega, e à explicitação de suas concepções, preocupações educacionais e de melhoria de sua prática na EJA.

Cursista A: "[...] Acho que um problema [...] interessante, seja uma análise de uma conta de luz, para podermos fazer a associação a função afim."

Cursista B: "[...] temos que comentar que na conta de luz existe os impostos embutidos e as taxas como por exemplo de iluminação pública da prefeitura.

Cabe, portanto, destacar que, a formação continuada em ambientes virtuais de aprendizagem contribui com o compartilhamento de experiências e de informações e com a rediscussão de práticas e ações que visem o aprimoramento da aprendizagem dos alunos (BRITTO, 2009). Com isso, a interação online deve estar embasada em uma perspectiva dialógica e as estratégias de formação a distância devem possibilitar a construção de significados crítico-reflexivos no que tange ao cotidiano profissional dos envolvidos e ao seu próprio aprendizado (BAIRRAL, 2007).

Cursista I: "Gostei muito da sua ideia colega Cursista G, de trabalhar o inverso, ou seja, dá para eles uma função já definida [...]."

Vargas, Fantinato e Monteiro (2005) reconhece que o aumento da oferta da EJA tem sido decorrente de instituições estarem atentas com o desenvolvimento e a construção da cidadania, pois os saberes pedagógicos podem colaborar com a prática, sobretudo se forem mobilizados a partir dos problemas que ela evidencia (PIMENTA, 1997). A dinâmica interativa online proposta a partir da prática na EJA possibilita que os participantes não apenas opinem, mas busquem caminhos e alternativas coletivamente. Dessa forma, o grupo de participantes pode analisar e contribuir com informações de sua própria vivência, além de buscar com o coletivo possibilidades de melhorias para o ensino na EJA. 
O posicionamento dos envolvidos no ambiente virtual permitiu a construção não linear da argumentação que foi socializada. À medida que as ideias foram compartilhadas, tiveram a possibilidade de serem reelaboradas, reavaliadas e orientadas por qualquer participante da discussão, incluindo o tutor, que também pôde interagir e realizar intervenções. Nesse sentido as mensagens subsidiaram uma dinâmica comunicativa, que propiciou o desenvolvimento profissional de forma interativa e colaborativa.

Como pôde ser visto o fórum é um ambiente de constante negociação. Na qual pode permanecer estável por um tempo, mas deve ser observado e mediado pelo tutor, a fim de possibilitar o desenvolvimento individual e do grupo. O tutor deve estar cada vez mais atento ao rumo do que está sendo discutido. De maneira que, sempre que necessário, poderá trazer o grupo para o objetivo proposto, aguçar o pensamento ou mesmo fornecer esclarecimentos sobre dúvidas e pensamentos errôneos. Segundo Bairral (2007) todas as intervenções, independente do tipo, são significativas para o desenvolvimento profissional, pois os professores cursistas refletem de forma crítica e metacognitivamente sobre suas compreensões e práticas docentes.

Como observado, as interações argumentativas ou informativas, configuram o espaço discursivo do fórum e podem potencializar o aprendizado. As argumentativas, em particular, possibilitam a continuidade da discussão, a colaboração no aprimoramento da informação postada e a construção do conhecimento docente (BAIRRAL, 2007). Todavia, as informativas não devem ser desprezadas, pois também trazem muitos elementos para o debate. No fórum analisado a presença destas foi para compartilhar sugestões de materiais, arquivos, sites etc. Esta troca também enriquece o acervo de informações do grupo e colabora com o aprendizado individual, conforme ilustramos.

Cursista Q: "Gostaria de disponibilizar aos colegas uma página de exercícios envolvendo funções...”.

Cursista M: "Tentei fazer algo parecido ainda bem que você postou, me deu mais segurança na minha escolha".

Cursista J: "É muito prazeroso compartilharmos nossas experiências nos fóruns".

Cursista N: "Ainda bem que você repetiu a sua resposta, ao item "a", eu havia gostado muito, porém, agora ficou bem claro, com isso pude aplicar aos meus alunos com mais segurança".

Cursista L: "[...] gostei muito e vou usá-la como mais um exercício de reforço".

Por meio do compartilhamento de práticas e de experiências os educadores foram dando continuidade ao debate e amadurecendo suas ideias iniciais, trocando e aproveitando atividades. Como se trata de um fórum de formação continuada esses elementos auxiliam o desenvolvimento profissional, agregando conhecimentos que podem não ter sido fornecidos no material didático do curso. Pimenta (1999) destaca que é essencial que se busque a reflexão dos caminhos tomados e dos resultados adquiridos da prática pedagógica. Mediante o compartilhamento online de informações a contribuição de um profissional pode ser agregada ao coletivo. Nessa cumplicidade e processo coletivo de troca de experiências e práticas que os professores vão constituindo seus saberes mediante reflexões constantes na e sobre a sua prática (PIMENTA, 1999), inclusive, fora do âmbito da EJA.

Por meio do compartilhamento de práticas e de experiências os educadores foram dando continuidade ao debate e amadurecendo suas ideias iniciais, trocando e aproveitando atividades. Como se trata de um fórum de formação continuada esses elementos auxiliam o desenvolvimento profissional, agregando conhecimentos que podem não ter sido fornecidos no material didático do 
curso. Pimenta (1999) destaca que é essencial que se busque a reflexão dos caminhos tomados e dos resultados adquiridos da prática pedagógica. Mediante o compartilhamento online de informações a contribuição de um profissional pode ser agregada ao coletivo. Nessa cumplicidade e processo coletivo de troca de experiências e práticas que os professores vão constituindo seus saberes mediante reflexões constantes na e sobre a sua prática (PIMENTA, 1999), inclusive, fora do âmbito da EJA.

A partir das análises realizadas foi possível observar o quanto as interações podem contribuir para o amadurecimento profissional e para a mudanças de posturas. As ideias e as sugestões compartilhadas no ambiente influenciaram os participantes. Muitos dos professores envolvidos aproveitaram as sugestões dos colegas. O interessante é que mesmo os docentes, atuantes em escolas diferentes e distantes fisicamente, se sentiram muito à vontade em compartilhar seus anseios e a se unir na busca de melhoraria para sua prática pedagógica na EJA. À medida que foram compartilhando suas experiências, os educadores foram notando que suas necessidades e anseios não eram muito diferentes e que tinham muito em comum para refletir e aprender no coletivo online. Sendo assim, o fórum se torna um ambiente frutífero no qual as individualidades podem ser juntar na busca de um benefício coletivo (ZULATTO, 2010) e, mediante interações variadas, contribuir para o desenvolvimento profissional de todos. 


\section{Referências}

BAIRRAL, M. A. Desenvolvendo-se criticamente em matemática: a formação continuada em ambientes virtualizados. In: FIORENTINI, D.; NACARATO, A. M. (Org.). Cultura, formação e desenvolvimento profissional de professores que ensinam matemática: investigando e teorizando a partir da prática. São Paulo: Musa Editora, 2005. p. 49-67.

. Discurso, interação e aprendizagem matemática em ambientes virtuais a distância. Seropédica: Edur, 2007.

O uso do chat e de fórum de discussão em uma educação matemática inclusiva. Seropédica: Edur, 2013. p. 65-112.

Tecnologias da informação e comunicação na formação e educação matemática. Seropédica: Edur, 2012.

BAIRRAL, M. A. et al. Realizando grupos focais como estratégia de reflexão e avaliação no desenvolvimento profissional de professores da EJA. Boletim Gepem, n. 68 , p. 45-67, 2016.

BARBERÀ, E.; BADIA, A.; MOMINÓ, J. M. La incógnita de la educación a distância. Barcelona: Cuadernos de Educación, 2001.

BEZERRA, C.; SANTOS, C. E. R. dos; FERNANDES, S. H. A. A. Contribuições de alunos cegos e de aluno surdos resolvendo problemas matemáticos em fóruns de discussão. In: BRITTO, S. M. de A. C. R. de. Saberes docentes e formação continuada na docência online. 2009. Disponível em: <http://etic2009.files.wordpress. com/2009/09/sheilane-britto.pdf>. Acesso em: 20 jun. 2015 .

CAMPELO, N. do C. S. Investigando percepções e desvelando reflexões do professor de matemática no processo de formação continuada. 2011. 147 f. Dissertação (Mestrado em Educação Matemática) - Universidade Bandeirante de São Paulo, São Paulo, 2011.

CAVALCANTI, L. de S. Cotidiano, mediação pedagógica e formação de conceitos: uma contribuição de Vygotsky ao ensino de geografia. Cadernos CEDES, v. 25, n. 66, 2005.

FÉLIX, S. F. A interação em fórum de ambiente virtual de aprendizagem. 2011. 109 f. Dissertação (Mestrado em Linguística Aplicada) - Universidade Católica de Pelotas, Pelotas, 2011.
GÓES, M. C. R. de; CRUZ, M. N. da. Sentido, significado e conceito: notas sobre as contribuições de Lev Vigotski. Revista Pró-Posições, v. 17, n. 2 (50), p. 3145, maio/ago. 2006. Disponível em: <http://www.proposicoes.fe.unicamp.br/proposicoes/textos/50_dossie_ goes_mcr_etal.pdf>. Acesso em: 15 mar. 2013

LOBATO, M. C. A. Mediações docentes em fóruns educacionais do curso de Letras da Universidade Federal do Pará. 2012. Tese (Doutorado em Linguística Aplicada e Estudos da Linguagem) - Universidade Católica de São Paulo, São Paulo, 2012.

MEDEIROS, L. G. F. de. Dando movimento à forma: as transformações geométricas no plano na formação continuada a distância de professores de Matemática. 2012. 125 f. Dissertação (Mestrado em Educação Matemática)- Universidade Severino Sombra, Vassouras, 2012.

MELLO, R. R.; BRAGA, F. M.; GABASSA, V. Comunidades de aprendizagem outra escola é possível. São Carlos: EduFSCar, 2013.

MISKULIN, R. G. S.; SILVA, M. da R. C.; ROSA, M. Formação continuada de professores de matemática: o desenvolvimento de comunidades de prática baseadas na tecnologia. TE\&ET Revista Iberoamericana de Tecnología em Educación y Educación em Tecnología, n. 3, p. 63-69, 2009.

OLIVEIRA, A. Formação continuada de professores de matemática à distância: estar junto virtual e habitar ambientes virtuais de aprendizagem. 2012. 85 f. Dissertação (Mestrado em Educação Matemática) - Universidade Federal do Mato Grosso do Sul, Campo Grande, 2012.

PIMENTA, S. G. Formação de Professores: Saberes da docência e identidade do professor. Nuances, São Paulo, v. III, setembro. 1997. Disponível em: <http://revista. fct.unesp.br/index.php/Nuances/article/view/50/46>. Acesso em janeiro de 12 de março de 2015.

Formação de professores: Identidade e saberes da docência. In: PIMENTA, S.G. (Org.) Saberes pedagógicos e atividade docente. São Paulo: Cortez, 1999.

Professor reflexivo: construindo uma crítica. In: PIMENTA, S. G.; GHEDIN, E. (Org.). Professor reflexivo no Brasil: gênese e crítica de um conceito. 3. ed. São Paulo: Cortez, 2005. 
FÓRUM DE DISCUSSÃO ONLINE | Gisele Pereira de Oliveira Xavier e Marcelo Almeida Bairral

SALDANHA, C. T. Interação nos fóruns de discussão: uma análise linguística. 2011. Dissertação (Mestrado em Educação) - Universidade Federal de Santa Catarina, Florianópolis, 2011.

SANTOS, C. E. R. dos. Interações de aprendizes cegos em fórum de discussão de um ambiente virtual de aprendizagem matemática. 2012. 143 f. Dissertação (Mestrado em Educação Matemática) - Universidade Bandeirante de São Paulo, São Paulo, 2012.

SCHEFFER, N.F; BRESSAN, J. Z.; CORREAA, R. M. Narrativas matemáticas: linguagem verbal e não-verbal, a argumentação e os registros de representação na discussão do tema funções com auxílio de tecnologias. In: JAHN, A. P.; ALLEVATO, N. S. (Org.). Tecnologias e educação matemática: ensino, aprendizagem e formação de professores. Recife: SEBEM, 2010. p. 125-144.

SILVA, K. W. A. da. A educação de jovens e adultos na formação de professores de matemática: expectativas e desafios. 2012. Dissertação (Mestrado em Educação) Universidade de São Paulo, São Paulo, 2012.

SILVA, L. P. da. As dificuldades de comunicação argumentativas em fóruns de discussão online com finalidade pedagógica. 2010. Dissertação (Mestrado em Linguística Aplicada e Estudos da Linguagem) - Universidade Católica de São Paulo, São Paulo, 2010.

SMOLKA, A. L. B. O (im)próprio e o (im)pertinente na apropriação das práticas sociais. Cadernos CEDES, $\mathrm{n}$. $50,2000$.

SOUZA, C. M. L. et al. Formação de conceitos por crianças com necessidades especiais. Revista Psicologia em Estudo, v. 15, n. 3, 2010.
VARGAS, S. M.; FANTINATO, M. C. C. B.; MONTEIRO, E. C. Q. Curso de extensão universitária em educação de jovens e adultos: discutindo a formação continuada de professores. Movimento, Niterói, n. 12, p. 119-132, 2005.

VIGOTSKI, L. S. A construção do pensamento e da linguagem. São Paulo: Martins Fontes, 2001.

VYGOTSKY, L. S. A formação social da mente. Tradução José Cipolla Neto, Luis Silveira Menna Barreto e Solange Castro Afeche. São Paulo: Martins Fontes, 1984.

WOODS, P. Investigar a arte de ensinar. Porto: Porto Editora, 1999.

XAVIER, G. P. O.; BAIRRAL, M. A. Análise de interações em um fórum de discussão do Projeto EJA da SEEDUC/RJ. In: ESQUINCALHA, A. C. (Org.); XAVIER, G. P. O (Org.); PINTO, G. M. F. (Org.); BAIRRAL, M. A. (Org.). O desenvolvimento profissional no Projeto Nova EJA da SEEDUC-/RJ: um olhar na formação continuada de professores que ensinam 108 Matemática. 1. ed. Rio de Janeiro: CECIERJ, 2014. v. 1. 114p

XAVIER, G. P. de O. Formação continuada para EJA: análise de interações docentes em matemática em um fórum de discussão. 2016. 116 f. Dissertação (Mestrado em Educação, Contextos Contemporâneos e Demandas Populares) - Instituto de Educação/Instituto Multidisciplinar, Universidade Federal Rural do Rio de Janeiro, Nova Iguaçu, 2016.

ZULATTO, R. B. A. Aprendizagem matemática colaborativa em um curso online de formação continuada de professores. In: JAHN, A. P.; ALLEVATO, N. S. (Org.). Tecnologias e educação matemática: ensino, aprendizagem e formação de professores. Recife: SEBEM, 2010. p. 125-144. 